\title{
TECNOLOGIAS DA INFORMAÇÃO E COMUNICAÇÃO E FORMAÇÃO DE PROFESSORES: SOBRE REDE E ESCOLAS
}

\author{
Katia Morosov Alonso
}

\begin{abstract}
RESUMO: A temática das tecnologias da informação e comunicação (TIC), aliada à formação dos professores, suscita reflexões sobre a natureza do trabalho pedagógico, com base nas mediaçōes técnicas e no desenvolvimento do processo formativo dos profissionais da educação nesse contexto. De fato, o uso de recursos tecnológicos sofisticados não tem assegurado transformações nas práticas pedagógicas nas escolas. $\mathrm{O}$ objetivo deste artigo se centra na análise desse fator, considerando que a lógica estabelecida pelas TIC implica trabalho em rede, lógica muito diferente do realizado nas e pelas escolas atualmente. É na fronteira dessas lógicas que são observados espaços que poderiam apoiar menos reducionismos no entendimento sobre TIC e formação docente.
\end{abstract}

Palavras-chave: Tecnologias da informação e comunicação. Formação de professores. Trabalho do docente.

\section{INFORMATION AND COMMUNICATION TECHNOLOGIES AND TEACHER TRAINING: ABOUT NET AND SCHOOLS}

ABSTRACT: The subject matter: information and communication tecnologies (ICT) associated to teachers' training stir up reflexions about the nature of pedagogical work based on technical mediations and about the development of the formative process of education professionals in this context. Indeed, the use of sophisticated technological resources has not guaranteed transformations in pedagogical practices in schools. The objective of this article is focused on the analysis of this factor, considering that the logic established by the ICT, and more recently, the converging of the media and the web,

Doutora em Educação e professora do Departamento de Ensino e Organização Escolar e do Programa de Pós-Graduação em Educação, do Instituto de Educação da Universidade Federal de Mato Grosso (UFMT).E-mail: katia@ufmt.br 
imply work on-line, a very different logic from the one currently applied in and by the schools. It is within the border of these logics that are foreseen spaces which could support less reductionism in the understanding about ICTs and teachers' training.

Key words: Information and communication technologies. Teacher's training. Teaching work.

\section{Introdução}

A

$s$ discussões sobre a incorporação das TIC $^{1}$ pelas escolas, conseqüentemente sobre a formação de professores, é tema candente não só pelas políticas públicas que se impõem em ambos os contextos, mas pela maneira apaixonada que defensores, e não defensores, tratam seus argumentos. Isso embota, muitas vezes, a compreensão sobre os sentidos e fundamentos que dão base a uma ou outra maneira de pensar essa questão. Há questôes de fundo que implicam pensar TIC, escolas e formação de profissionais que atuem em contexto mutante e avizinhado por lógicas que não são as trabalhadas por instituições como a escola.

Refletir sobre tais questōes é o objetivo deste artigo. Afinal, as TIC são produzidas e processadas em contextos que não os escolares. Pretende-se, contudo, que elas possam catalisar transformações nos modos de ensinar e aprender, no modo de ser professor.

\section{Globalização x educação: o anúncio de inovações}

Carrear o fenômeno da globalização e seus reflexos nos vários âmbitos da vida humana é importante, à medida que, por meio de uma série de reconstruções de nosso cotidiano, podemos entender como foi alterada nossa percepção sobre o mundo. Tempo, espaço e trabalho são afetados pelas dinâmicas que reconfiguram nossas relaçôes, nossa maneira de ser/estar no mundo. Embora seja um processo marcadamente econômico, há nisso uma lógica que impõe outros modos de organização da vida, que se espraia pelo social, cultural, político-educacional, demandando rearranjos e criaçôes humanas que nos possibilitem interagir com o novo, compreender o desconhecido. É neste contexto que a formação de professores também se encerra, seja pelos desafios gerados na e pela 
forma que o conhecimento é produzido e socializado, seja pelos dilemas postos aos sistemas públicos de ensino em qualquer de seus níveis. Simultaneamente, no caso brasileiro, temos, para além desse contexto, demandas relacionadas com a universalização do ensino fundamental e médio, que expressam, por um lado, a necessidade de formar contingente maior de professores e, por outro, a necessidade de dispor de alternativas de formação que transcendam os modelos mais tradicionais de promovê-la.

De fato, as transformações atingem as instituições escolares de modo contundente. Seus princípios são questionados, currículos são revistos, avaliações são implementadas, tendentes a dotar qualidade ao ensino/aprendizagem. Padrões que normalizem a escolarização são admitidos. Há também incentivo para novas experiências educativas pautadas, geralmente, por políticas que, ao financiarem determinados programas, tentam implicar as escolas em outras dinâmicas de ensino/ aprendizagem.

Nas experimentações propostas para as escolas, destacam-se, numa esfera atual e global (Gilleran, 2006), as relativas ao uso mais intenso de computadores/TIC. Junto com a compra de equipamentos, softwares, entre outros artefatos, são constituídos programa s e/ou projetos de formação de professores, com o objetivo de transformar o cotidiano escolar. Pretende-se que a incorporação das TIC pelas escolas seja elemento catalizador de mudanças significativas na aprendizagem dos alunos.

No entanto, como observado em vários estudos (Armstrong \& Casement, 2001; Corea, 2004; Blikstein, 2006), os artefatos mais sofisticados e os computadores ligados à internet não têm sido suficientes, podem ser necessários, para que a aprendizagem escolar seja, significativamente, afetada. Essa discussão é complexa, porque a aprendizagem aqui referida tem que ver com parâmetros escolares e de escolarização. Há outros estudos que demonstram, contudo, como as novas gerações têm sido influenciadas por maneiras diferentes de, por exemplo, ler e escrever, incorporando linguagens e modos "do navegar na internet" ao fazer escolar. Bauerlein (2007) afirma que, atualmente, as crianças e jovens, que convivem mais de perto com computadores, já não lêem atentamente e concentradamente textos, eles mais "escaneiam" as informações que lhes interessam, detendo-se pouco no conjunto do escrito. Silva, Freire e Almeida (2006), em pesquisa realizada 
Tecnologias da informação e comunicação e formação de professores...

em escola fundamental pública, discutem a incorporação de emotions e da linguagem cifrada, comuns nas "salas de bate-papo", nos textos produzidos em sala de aula. Se, no primeiro caso, há alerta quanto ao modo de leitura "escaneado", no segundo argumenta-se em favor da produção de significados relacionados com os processos do ler e do escrever.

De todo modo, vivemos momento em que o uso das TIC nos ambientes escolares começa a ser relativizado (Blikstein, 2003). O entusiasmo inicial é arrefecido, considerando os resultados efetivos de programas como o de compra de computadores para as escolas públicas e as condiçôes limitantes para serem utilizados. Mais recentemente, conforme o noticiado (Folha de S. Paulo, 8 jul. 2008, p. C3), o governo federal brasileiro interrompeu o programa "Um computador por aluno", em razão do preço dos laptops. Em substituição, foi lançado o programa "Computador portátil para professor". ${ }^{2}$ Por meio da facilitação de financiamento e desconto especial, os professores poderão adquirir seus equipamentos, isso como parte de política de informatização das escolas. Da esfera pública transfere-se para a esfera privada a consecução de políticas de informatização das escolas!

Entretanto, mais que as limitações do uso dos equipamentos, bem como da apropriação das TIC pelas escolas, há questão de fundo que determina a incorporação deles/as pelos alunos e professores. E, daqui, retornamos ao início do texto, à afirmação de que o processo de globalização terminou por afetar nossa percepção de mundo, por implicar lógica de produção distinta daquela do final da Segunda Guerra Mundial. As TIC vão, pouco a pouco, moldando e sendo moldadas nessa lógica, convertendo-se, atualmente, na expressão do sincronismo de tempos e espaços que não se coadunam aos tempos e espaços escolares. Há descompasso - isso é claro - entre a produção das TiC e a produção escolar. Este é o cerne da questão TIC versus escola, portanto da formação de professores. Longe de assumir caráter prescritivo - são muitos os estudos que indicam as melhores formas com que as escolas poderiam utilizá-las (Paloff \& Pratt, 2002, 2004; Kenski, 2007) -, refletir sobre a lógica em que surgem as TIC e a lógica escolar contribui para pensarmos não em sucessos e fracassos, mas na possibilidade de pontos de confluência em movimentos paralelos, seja pela concepção que um e outro trazem no tratamento das informaçôes, seja pelas iniciativas de sincronicidade/interação que os marcam. 
Tempos e espaços em rede. E a escola?

O fenômeno da globalização, ao ensejar formas de repensar/compreender aspectos e fatores que se impōem às populações, de modo mais ou menos universal, ${ }^{3}$ gera processos de caráter econômico e social que influenciam nas decisões no setor educacional.

Estudos como o de Santos (1997), Castells (1998), Armstrong e Casement (2001), Mattelart (2001) e Blikstein (2003) nos ensinam diferentes influências desse fenômeno em várias dimensōes de nossas vidas: do espaço geográfico à incorporação de tecnologias ao nosso cotidiano, e como isso nos reporta para um mundo, aparentemente, "de ponta-cabeça". ${ }^{4}$

No início dos anos de 1960, Mcluhan (1995) anunciava a transformação da sociedade mecanizada, marcada pela fragmentação, seriação e seqüência, para outra, marcada pela simultaneidade, isso em decorrência da "velocidade instantânea" (p. 26) propiciada pela eletricidade. Mais do que cunhar a expressão "aldeia global", ele trouxe à cena a discussão relevante sobre a produção tecnológica e a forma como compõe outras percepçôes sobre o cotidiano, implicando fazeres que, ao conservarem o anterior, são ressignificados, comportando novas estruturas e configurações. Esta dinâmica anterior/atual, que conserva e recria, é importante para compreendermos o movimento que fundamenta o aflorar das novas tecnologias da informação e comunicação. Novas porque se incorporam e são incorporadas numa outra estrutura: a da sincronicidade.

Santos (1996) nos ajuda a pensar sobre isso. Ao analisar como tempo e espaço são reapropriados no movimento da globalização, lembra que um dos elementos que faz diferenciar o momento atual dos anteriores é sua "unidicidade técnica" (p. 154), que atinge a todos, de maneira hegemônica. Resultado de processo histórico/econômico pós-século XIX, o autor trata da dinâmica incorporação de técnicas de produção a heranças materiais mais permanentes, que moldam nossos fazeres e compreensão do mundo. Essa plasticidade com que as técnicas são incorporadas ao nosso cotidiano é o que define a unidicidade por ele referida.

A possibilidade de conectar o que está disperso em momentos da produção faz com que seja concentrado o controle sobre o que é produzido, definindo uma nova realidade, caracterizada por 
Tecnologias da informação e comunicação e formação de professores...

(...) convergência dos momentos (...) que corre paralelamente ao desenvolvimento das técnicas, sobretudo as técnicas da velocidade e da medida do tempo. A conquista da velocidade permite um deslocamento mais rápido das coisas, dos homens e das mensagens. (...) e alargamento dos contextos (...) as novas possibilidades de fluidez que estão na base dessa formidável expansão do intercâmbio. Aumenta exponencialmente o número de trocas e estas ocupam um número superlativo de lugares em todos os continentes, multiplicando-se o número e a complexidade das conexões. Estas passam a cobrir praticamente toda a superfície da Terra. (Santos, 1996, p. 159 e 202)

Tempo e espaço são diretamente afetados pela "unidicidade das técnicas", conformando outros modos e formas de nos relacionar. Agora, a idéia de fluxo se sobrepõe à de espaço e tempo fragmentados. Neste caso, a metáfora da rede $\mathrm{e}^{5}$ aparece como expressão das conexóes possibilitadoras de criar e manter "fluxos", não só pelas linhas que se entrelaçam em sua consecução, como também pelos nós que a sustentam. É, pois, nessa superfície reticulada que, segundo Santos (1996), podemos conceituar "rede" em duas grandes matrizes: "a que apenas considera o seu aspecto, a sua realidade material, e uma outra, onde é também levado em conta o dado social". No primeiro caso, é considerada a infra-estrutura que permite o "transporte de matéria, energia e informação, e que se inscreve sobre um território onde se caracteriza pela topologia dos seus pontos de acesso ou pontos terminais, seus arcos de transmissão, seus nós de bifurcação ou de comunicação". No que tange o social "pelas pessoas, mensagens, valores que a freqüentam" (p. 208-209).

O surgimento das TIC é, então, conformado e se conforma por e nesse contexto. Se pelas técnicas são originadas tecnologias, as TIC são expressão da rede, manifestada por elas. McLuham (1995), ao argumentar que as tecnologias convertiam-se em nossas extensóes, justamente por recomporem nossos ambientes vivenciais, manifestando-se nas relações entre os sentidos e nas estruturas da percepção, reconheceu também que, quando assim entendidas, elas - tecnologias - sofrem pouca resistência em sua incorporação, fazendo com que não tenhamos consciência de seu conteúdo. O autor argumentava que "o conteúdo da escrita ou da imprensa é a fala, mas o leitor permanece quase inteiramente inconsciente, seja em relação à palavra impressa, seja em relação à palavra falada” (p. 33). 
As tecnologias, como nossas extensões - e as TIC parecem exacerbar ainda mais essa perspectiva -, "naturalizam" a rede. Esquecemonos, não raro, que é por meio dela que os fluxos da produção se movimentam, dando origem a espaço/tempo sincrônicos, convergentes. $\mathrm{Na}$ superfície reticulada, com linhas entrelaçadas e nós, há que atualizar o que existe como potência. Nessa superfície não há centro, mas topologias e conectividade global (Lèvy, 1993).

A referência a esta compreensão é fundamental para entendermos a lógica que subjaz ao uso das TIC. Conexão, conectividade, fluxo são conceitos que sustentam seu uso, implicando outros ambientes e formas de pensar. Termos como fronteira, territórios, lugares são substituídos pela ilusão do fluxo, até porque, como nos lembra Santos (1996), o conteúdo técnico que permite comunicações permanentes no mundo inteiro, ininterruptamente, é indispensável na estruturação do conjunto das atividades econômicas, sendo as informações subsumidas por esse campo, criando monopólios para sua circulação.

Nesse sentido, Lubar (1993) chama a atenção para aquilo que denomina de "determinismo tecnológico". As TIC, ao se estenderam a todos os âmbitos da sociedade humana, modificariam nossas percepçôes sobre o sociocultural e sobre o político-econômico, fazendo brotar uma ideologia que traz, em seu âmago, a idéia de acesso irrestrito e universal à informação, confluindo na certeza de que a digitalização, como realidade inevitável, transformará o mundo.

Tanto é assim que, nos últimos anos, falamos, escrevemos e prescrevemos os caminhos que a escola teria de seguir para fazer frente à chamada sociedade da informação (Ianni, 1996) - para outros, a sociedade do conhecimento (Lèvy, 1993). A possibilidade da rede, da interação por meio dela, e a pressão provocada pela expansão dos sistemas informacionais-técnico-científicos dão origem à idéia de que agora informação e conhecimento fluem rapidamente, cedendo lugar à inteligência coletiva. Seus defensores propõem novo princípio de estratificação social. Porém, agora, a relação com os meios de produção não seria o fator relevante para a determinação das relações sociais, as diferenças seriam marcadas pela riqueza ou carência de informação e conhecimento que possua cada pessoa. Tal pensamento faz com que o problema da formação, principalmente a técnica e profissional, seja valorizado e institui-se o uso das tecnologias como nova panacéia 
Tecnologias da informação e comunicação e formação de professores...

educativa. Porém, como nos alerta Sancho (2006), na sociedade da informação e informatizada as TIC constituiriam elemento-chave e sua incorporação aos contextos educativos, em função do modelo econômico atual, tem implicado usos mecânicos e eficientistas, definhando suas potencialidades de uso mais criativo.

O fato é que a demanda por mais escolarização, pela universalização da escola fundamental e média, e por níveis mais elevados de educação, põe-se como condição necessária e suficiente para o avanço das forças produtivas ou de ajuste às demandas de trabalho. A contradição está justamente na crença de que a escola poderá solucionar tais problemas e, por isso, a sociedade exige "escola de qualidade", entendida como extensão do mundo economicamente produtivo. As formas tradicionais de "transmissão do conhecimento" são também questionadas, constrangendo a busca por novos atributos culturais, em conseqüência, escolares.

Esses fatores determinam e condicionam, pouco a pouco, o sentido e o significado da escola, apontando para enormes contradições entre o que se pretende e o necessário a uma formação que "atenda ao mercado". No cenário educacional brasileiro, isso vem marcado pelo aligeiramento, pela produção em escala e centralizada de programas de formação.

$\mathrm{Na}$ denominada sociedade da informação e do conhecimento, "a escola perdeu o monopólio de transmissora de saber" (Rodriguez, 1996, p. 115). As fontes em que crianças, jovens e adultos buscam e encontram informações seriam, hoje, muito diversas. Em muitos casos, com o uso da informática e das redes de comunicação, as informações são transmitidas com grande eficácia, fazendo emergir o discurso de que a escola e os centros educativos devam descobrir ou ressignificar seus papéis ou funções, de maneira que as TIC sejam utilizadas com maior eficácia pedagógica. Reforça-se, assim, na perspectiva de Barreto (2004), o sentido de desterritorialização dessa instituição.

A incorporação de tecnologias nesse âmbito contribui, no mais das vezes, para acelerar a crise de identidade dos professores. Quando são integradas ao fazer pedagógico, necessitam ser significadas. $\mathrm{O}$ sentido do objeto técnico na prática escolar termina por definir não somente determinado uso, mas a sedimentação de culturas. A história da educação e da pedagogia ensina pensar sobre tais processos. Se, com 
a aparição dos livros, houve questionamentos sobre a legitimidade do professor como "depositário" do saber, o caso das TIC traz à tona a discussão sobre o papel profissional dos professores nos processos de ensino/aprendizagem.

Do ponto de vista pedagógico, o uso das TIC no contexto escolar e as significações sobre elas têm implicado transformações que relativizam a função do professor como transmissor de conhecimento, deslocando o centro da questão para o "protagonismo" dos alunos. O problema é que a escola, como instituição, está ainda marcada pela lógica da transmissão, fazendo colidir a lógica das TIC e a lógica escolar.

A utilização educativa/pedagógica das TIC, vistas como recurso e material, seria congruente com a necessidade de incorporar aos processos de ensino/aprendizagem codificações diferentes, que estariam sendo elaboradas nas distintas manifestações da cultura em nossos dias. A ocorrência de tal fato faria supor a constituição de processos de mediação cultural, mais amplos e variados que os conhecidos tradicionalmente, primeiro pela transmissão oral e, depois, pela transmissão escrita.

Os novos processos comunicacionais produziram percepções e construções diferentes quanto à produção e à socialização dos conhecimentos historicamente acumulados. Independentemente do uso que se faça da rede, o "laboratório de informática" das escolas, como aponta Josgrilberg (2006), não tem "enredado" alunos e professores numa rede que seja significativa nos processos de ensino/aprendizagem, no interior da instituição escolar. Por meio de pesquisa com professores de rede municipal de ensino, com atuação no ensino fundamental, o autor discute a forma pela qual estes laboratórios chegam à escola. São identificados problemas que vão desde a falta de espaço e de instalaçóes adequadas para as máquinas - salas de aula e de professores, refeitórios e depósitos foram utilizados precariamente para tanto -, até a falta de projetos que possam ressignificar, no interior de uma cultura escolar bastante sedimentada, o uso dos equipamentos informáticos, estes que possibilitariam trabalhar em rede.

Não se trata de, apenas, discutir a incorporação das TIC nas e pelas escolas. $\mathrm{O}$ resultado do ensino com uso mais intenso, por exemplo, de tecnologia eletrônica tem redundado em sistemas de baixíssima interação, que replicam grosseira e indefinidamente uma matriz de aula como as denominadas, mais recentemente, de teleaulas. Scheibe (2006) 
Tecnologias da informação e comunicação e formação de professores...

e Zuin (2006, p. 951) já apontaram a "pulverização da autoridade pedagógica”, quando se lança mão de mediação técnica, acompanhada de serviços de apoio a essa mediação, como é o caso dos tutores na educação a distância, principalmente no ensino superior. A questão é, sobretudo, relacionada com a função da escola, a forma pela qual ela se organiza na e para a oferta educacional, e isso é pouco trabalhado. Parte da produção sobre TIC e escola (cf. Pallof \& Pratt, 2002, 2004; Kenski, 2007) reporta aos novos atributos que são requeridos aos professores, alunos e gestores como indicativos da transgressão aos modelos formalistas de educação, abandonando-se a escola e os professores nessa tarefa - transgressão. Como observado por Josgrilberg (2006), embora as políticas públicas anunciem a necessidade da inovação e distribuam equipamentos informáticos como expressão desta vontade, a estreita passagem do anterior para o novo é, ainda, responsabilidade dos professores.

Transfere-se, desse modo, para as "mãos" dos envolvidos diretamente com as práticas escolares/pedagógicas a empreitada da transformação, cabendo-lhes recriar fazeres e saberes de lógicas estranhas e alheias a seu cotidiano. Evidentemente que o envolvimento dos professores e professoras nesta tarefa é fundamental, e a constituição dos significados sobre as TIC, do ponto de vista escolar e pedagógico, só poderá vingar com o envolvimento destes profissionais. $\mathrm{O}$ problema é que a incorporação das TIC no contexto escolar aparece como mais uma das pressões para alcançar os objetivos da qualidade na educação, constrangendo mudanças, sobretudo no perfil profissional dos professores. Nesse processo, é necessário considerar as bases sobre as quais o "movimento" para o novo pode ser caracterizado.

Assim, as demandas por formação, resultantes das mudanças ligadas à nova ordem econômica, em grande parte dos países ocidentais, indicam transformações profundas na organização e na gestão do trabalho, no acesso ao denominado "mercado" e na cultura cada vez mais mediatizada e mundializada (Castells, 2003). Estas transformações, por sua vez, imprimem mudanças efetivas nos sistemas educativos. O papel da educação na sociedade atual está ligado à possibilidade de responder, com alguma rapidez, à incorporação de meios técnicos e de uma flexibilidade maior às condições de acesso a currículos, metodologias e material. Na chamada sociedade da informação, ou do saber, 
em que mais rapidamente a formação inicial se faz insuficiente, as tendências mais fortes apontam para a "educação ao longo da vida" (Belloni, 1999), mais integrada ao trabalho e às expectativas e anseios mais individualizados.

Tais mudanças comportam transformações profundas nas instituições escolares. Transformações que dizem respeito aos processos mais "operativos" de viabilizar a formação que põe em relevo questionamentos sobre a natureza do trabalho do docente e sobre a cultura escolar, que possam imprimir novo "olhar" sobre a educação. Se esse é um campo em que se verificam demandas crescentes por formação, se as reformas propostas seguem, quase sempre, uma idéia de qualidade fundada na racionalidade administrativa, mais que na qualidade dos conhecimentos, se é urgente avaliar os níveis de formação da população escolar, se a utilização das TIC é algo inexorável (Lévy, 1993), cabe perguntar: Até que ponto a escola poderá se atualizar, considerando a mediação dos conhecimentos com vista à formação? Redescobrir e reafirmar uma lógica para a escola não significa apartá-la do mundo tecnológico, mas reconhecer que a tarefa de educar requer certos princípios, processos e procedimentos que não coincidem com os modos de operar em rede por meio das TIC. Estabelecer isso não denota, absolutamente, anacronismo entre o fazer escolar e o fazer social mais amplo. Antes, nos sugere entender como se dão os processos da aprendizagem, considerando todas as suas dimensões, bem assim as implicações pedagógicas disso na instância escola. Não basta prescrever maneiras de trabalhar com programas e aplicativos que estão na internet, ${ }^{6}$ mas, conforme afirmado por Abrahamson, Blikstein e Winlensky (2007), trata-se de trabalhar com o computador como objeto social. Sem dúvi$\mathrm{da}$, isso faz questionar os modelos mais "fechados" de escolarização, que ignoram a aproximação de mídias variadas, introdutoras de novos códigos e linguagens que precisam ser entendidos até para serem mais bem aproveitados. Questões de ordem mais socioafetiva, de interação, de motivação e de integração dos conhecimentos às experiências de vida são assuntos que influenciam, mais e mais, o ideário educativo-formativo.

Isto não é novo. Desde, aproximadamente, metade do século xx, os métodos de ensino fundados na transmissão de informações têm sido criticados. A incidência de novos personagens e novas necessidades sugere, ${ }^{7}$ cada vez mais, reformulaçôes profundas nos sistemas escolares. 
Tecnologias da informação e comunicação e formação de professores...

Os educadores têm claro hoje que nem o professor, nem o aluno têm controle do processo da aprendizagem. Ambos os sujeitos/personagens participariam dinamicamente dele.

Portanto, o problema da inovação escolar, mais que as questões sobre o uso das TIC, aponta para a incorporação de ideário que possa, ao mesmo tempo, recriar o cenário escolar, ensejando uma lógica que afirme o papel da escola nos processos de ensino/aprendizagem, corroborando práticas pedagógicas que poderão, ou não, ser afetadas pelas TIC.

\section{A formação de professores e o contexto de mudanças}

O cenário mutante, na escola e em seu entorno, constitui situação anacrônica entre as práticas docentes e as expectativas sobre a função da escola na atualidade. Existe um sentimento geral de que a escola e, mais particularmente, os professores "falham" no cumprimento de seu trabalho.

Para Esteve (1999), a situação dos professores diante das mudanças que ocorrem na escola é comparável a um grupo de atores que trajam vestimentas de determinado tempo e que, sem nenhum aviso anterior, mudam-lhes os cenários e as falas. Para ele, a primeira reação do grupo seria de surpresa, depois tensão, associadas a forte sentimento de agressividade. A conseqüência deste tipo de exposição desembocaria na demonstração pública da fragilidade a que estão expostos os professores. A metáfora por ele trabalhada - da cena de um teatro e a atuação dos professores - aponta para um contexto profissional diferente daquele em que a maioria dos professores se formou e atua. Conforme o autor, "as reaçôes diante dessa situação (de fragilidade) seriam muito variáveis; porém, em qualquer caso, a expressão 'mal-estar' poderia resumir os sentimentos do grupo de atores ante uma série de circunstâncias imprevisíveis que os obriga a atuar em um papel grotesco" (Esteve, 1999, p. 97).

Essa situação é utilizada por Esteve (op. cit.) como "materialização" do sentimento de "mal-estar" vivenciado pelos professores. O termo mal-estar aparece como conceito na literatura pedagógica e pretende resumir o conjunto de reaçóes dos professores como grupo profissional "desajustado", em conseqüência das transformações sociais, políticas e econômicas da atualidade. Esse "mal-estar" pode ser reconhecido na idéia 
generalizada de que a escola está em crise. Para muitos, o que determina tal crise é a dimensão conservadora, de reprodução do sistema gerador de esquemas normalizantes de adaptação que conduzem ao conformismo e ao acolhimento acrítico de sujeição; ou ao resultado de um imenso esforço na tentativa de encontrar um "lugar" social para os que historicamente foram desprovidos desse direito. $\mathrm{Ou}$, até mesmo, à procura de um "lugar" em que pudéssemos satisfazer aspirações de caráter mais individualizado.

O "quadro" apresentado por Esteve descreve, bem, as impressões e sensações dos professores quando enfrentam situações em que seu repertório de saberes já não é suficiente. Isso determina, por sua vez, as críticas que os consideram responsáveis imediatos pelos fracassos dos sistemas educacionais. A tentativa de superar o anacronismo entre as práticas docentes e as demandas educativas vem "conformando" algumas das propostas de formação do professorado que têm por base a idéia de "profissionalização", isso como primeiro passo no resgate do trabalho do docente, em sentido amplo.

A compreensão sobre a natureza do trabalho do docente, das características de sua constituição, vem, ultimamente, imprimindo novas propostas de formação de professores, cuja ambição ou objetivo seria superar, ou minimizar, o quadro elaborado.

As discussões sobre a formação de professores e sobre a relevância que estes assumem no contexto educativo têm posto em destaque a compreensão da natureza do trabalho do docente. Tenta-se, dessa maneira, estabelecer os requisitos mínimos do estatuto profissional da profissão do docente e, como conseqüência, os requisitos mínimos para a formação desses profissionais. Destaca-se na discussão a idéia da mediação, portanto, de profissionais que pudessem, competentemente, realizá-la.

O fato de valorar a mediação no processo do conhecer traz à cena outros conceitos. Assim, interação e interatividade aparecem como complementares ao ensinar/aprender. Junte-se a isso a idéia de que, se a informação circula, se está em fluxo constante de produção, transcendendo a escola, a situação para advogar a necessária transformação da profissão do docente igualmente se materializa. Mais que formação, exige-se a mobilização de conhecimentos que possam ser transformados em ação, compreendidos agora como "competências". Estas competências são 
Tecnologias da informação e comunicação e formação de professores...

entendidas como "capacidade de mobilizar múltiplos recursos numa mesma situação, entre os quais os conhecimentos adquiridos na reflexão sobre as questões pedagógicas e aquelas construídas na vida profissional e pessoal, para responder às diferentes demandas das situações de trabalho" (Parecer CNP/CP 09/2001, p. 23). Barreto (2004) apresenta discussão importante sobre isso, indicando o atravessamento do uso das TIC nos processos de formação dos professores.

Como "marcos fundantes" desse processo, vimos despontar, nos últimos anos, pesquisas e estudos que tentam definir a profissão/professor (cf. Libâneo, 2006). ${ }^{8}$ A determinação da natureza do trabalho do docente poderia indicar formas que pudessem superar a aprendizagem receptiva. Nessa perspectiva, uma redefinição da formação do professor teria por objetivo fomentar ou promover aprendizagens ativas, intentando superar a simples aquisição de conteúdo escolar preestabelecido.

O movimento para outras propostas de formação do professorado implica, neste caso, trabalhar com conceitos como os de profissionalidade e autonomia. Profissionalidade entendida como processo de resgate de identidades profissionais, e autonomia entendida como processos de autoformação, de autogestão profissional e de constituição de espaços de trabalho reflexivos. Sobretudo porque o labor do docente pressuporia atividades de caráter teórico-prático, ou melhor, de compreensão das práticas estabelecidas por e na escola. Ainda que esses conceitos assumam interpretações muitas vezes diferentes, o fato é que têm sido tomados como princípios para a instauração de políticas de formação dos professores, incluindo idéias de natureza reflexiva/intelectual da profissão/professor (Freitas, 2003).

A ocorrência de discussões, como as até aqui apontadas, inserese em um contexto mais amplo, como tendências em cenários de formação do professorado. Cenários que expressam uma mesma convergência de fatores: o esgotamento da função do docente como mera instrução; a crítica generalizada ao papel da escola em nossos dias e novas demandas educacionais. Acresça a necessidade de superar modelos de educação tecnificada, entre outros de caráter mais geral, como os de natureza econômica - as políticas do "Estado menor" - e política - a vigência de modelos excludentes de desenvolvimento. Isso significa que, seja no âmbito das pesquisas, seja no âmbito das políticas públicas, a 
concepção do professor como profissional intelectual/reflexivo dá a tônica às propostas de formação.

É importante reforçar que a discussão sobre a formação de professores, tendo por base a visão reflexiva, assume, no contexto brasileiro, aspectos não pouco contraditórios. Existem, por um lado, as proposiçôes oriundas dos movimentos e associaçóes docentes e, por outro, a implementação de políticas que se apropriam dessa noção, tomandoa numa perspectiva de incremento da autonomia entendida, simplesmente, como forma de baixar custos no setor educacional (Contreras, 1999).

Daqui vemos espraiada a concepção de que as TIC poderiam se converter nas "ferramentas" que solucionariam a aplicação desse tipo de formação. Por mais contraditórios que o movimento entre as políticas oficiais e os princípios estabelecidos por e nas reivindicações docentes possam parecer, considerando a existência de um sentimento de usurpação de significados históricos, quando se trata da idéia de profissionalização do professor, seria nessa dinâmica que estariam postos os projetos/programas em cuja base vemos, se não todos, pelo menos parte dos conceitos, idéias e ideais nascidos na discussão mais coletiva desse assunto.

A perspectiva de uso mais intenso das TIC na formação de professores, e pelas escolas, carece de significação quando, como apontado por Barreto (2004), se trata de sua apropriação em sentido cultural/ pedagógico amplo. A lógica da rede é, evidentemente, base para que esse movimento possa ser constituído. Isso já fora indicado por Pretto (2002). O problema é que se persiste na mesma concepção de uso das TIC com consequiências graves para os sistemas escolares.

Fumagalli (2007), ao discutir o desenvolvimento de rede educativa na Argentina, lembra que, para trabalho dessa natureza, é imprescindível o acatamento de decisões horizontais, que venham a contar com as escolas nos processos de desenvolvimento curricular. Observa também que, na América Latina, as mudanças educativas se deram, geralmente, na perspectiva "de cima para baixo" (p. 149), impedindo dinâmicas de maior cooperação entre os estabelecimentos escolares e organismos governamentais. Com a instalação da "Nova CAPES", temos hoje organismo que, entre seus objetivos, propõe elaborar políticas e diretrizes para a formação inicial e continuada de professores; "opinar 
Tecnologias da informação e comunicação e formação de professores...

sobre critérios e procedimentos para fomento a estudos e pesquisas relativos à orientação e conteúdos curriculares dos cursos de formação inicial e continuada de profissionais do magistério da educação básica (...)", tendentes à construção de sistema nacional de formação na modalidade presencial e a distância. ${ }^{9}$ Apesar de se alardear o novo - a sociedade da informação e do conhecimento -, onde, presumidamente, não só consumiríamos, mas produziríamos informaçōes, os professores, como "ponta" da inovação, terão muito pouco que falar sobre sua formação. Haverá quem os oriente sobre quais competências profissionais se deseja para que o sistema público de ensino seja transformado.

Além disto, o estabelecimento de rede, com vista ao trabalho pedagógico, aponta para entendimentos de uso das TIC muito contraditórios. As soluções vão desde o "ensino assistido por computador", passando pela "alfabetização informática", até a proposta de utilização das TIC como "ferramentas educacionais" (Ponte, 2000, p. 71-73). Cada uma dessas respostas carreia competências diferentes para o professor: no primeiro caso, os atributos profissionais estariam vinculados ao de maximização dos objetivos educacionais, o computador se converteria em fonte de informação; no segundo, a maximização técnica do uso da máquina faria supor a introdução de novas disciplinas escolares, como "Informática na Educação"; e seu uso técnico seria o atributo principal. Por último, a idéia das TIC como recursos e instrumentos na e da aprendizagem implicaria o professor no rearranjo criativo, de nenhum modo intencional, do processo de ensinar e aprender. A criatividade surgiria como atributo, e as TIC seriam possibilitadoras de transformação das culturas escolares.

A forma pela qual as TIC são utilizadas nas escolas e pelos professores realça que o modelo escolar, ou melhor, a lógica que subjaz à instituição escolar atrita, em nossos dias, com a lógica da rede, originando "rugosidades" entre elas (Josgrilberg, 2006). O atrito entre uma lógica e outra póe em cena o papel dos professores. Afinal, se na lógi$\mathrm{ca} /$ rede não há centro, mas produção cooperativa e extensa, como trabalhar com a lógica da aprendizagem dirigida e seqüenciada exigida pela educação escolar? As respostas variam: as escolas teriam de se identificar com as TIC, numa perspectiva de interação necessária à aprendizagem, e os professores assumiriam papéis menos autoritários, mais horizontais (Kenski, 2007); ou, ainda, que as aprendizagens passariam 
a se configurar mais pela ação de grupos, operando por meio de interaçôes coordenadas consensualmente, tendo o professor como moderador (Carneiro \& Maraschin, 2005), entre outras.

De todo modo, reconhecemos, pouco a pouco, que a introdução de novos artefatos técnicos nas escolas não redunda em melhoria efetiva do processo ensino/aprendizagem. Sem a conotação alarmista que Armstrong e Casement (2001) imputaram ao seu trabalho, é verdadeira a advertência de que "a aquisição do conhecimento científico não necessariamente depende de intervençôes tecnológicas, pois as observações e as experiências humanas são muito mais importantes" (p. 202). Isso é essencial no trabalho pedagógico. Nossas observações, experiências, os modos pelos quais convivemos e nos relacionamos fazem significar, inclusive, o uso das TIC. Talvez esta seja uma das razóes para que as justificativas da ocorrência delas nos ambientes escolares sejam atravessadas por filigranas explicativas. Conclamam-se desde as teorias de aprendizagem de caráter sociointercionista, incluindo o uso de ferramentas que sustentem os processos de comunicação para explicar o porquê de outra mediação que, necessariamente, deverá ser assistida, no caso da escola, por um professor! Os atributos que se pretendem novos e revolucionários têm que ver com nosso conhecido bom professor: aquele que efetivamente se envolva no e com os processos do ensinar e aprender.

Assim, os desafios postos aos sistemas escolares, bem como na formação dos professores em tempos de TIC, convergem, cada vez mais, para o entendimento da instituição escolar como espaço privilegiado de socialização e emancipação das crianças e jovens, considerando para tanto a aquisição de conhecimentos científicos, culturais e sociais que poderão, ou não, estar inscritos na lógica da rede. De fato, a discussão sobre as TIC e a formação de professores põe na cena educacional o debate sobre o lugar das tecnologias nesse território. Se as pressões de caráter técnico-científico-informacional, marcadas pela interação entre ciência e técnica, comprimem espaço e tempo em fluxos, tornando-os sincrônicos, também é preciso reconhecer, como Santos (1996, p 190), que "o novo não é difundido de maneira generalizada e total”, embora os objetos técnico-informacionais o sejam mais rapidamente. Esse movimento em fluxo é marcado, então, por dinâmicas diferentes que se moldam à incorporação desses objetos, 
Tecnologias da informação e comunicação e formação de professores...

tecnificando e instrumentalizando nossos fazeres/saberes. O conhecimento nesse movimento é tomado como recurso, "participando do clássico processo pelo qual, no sistema capitalista, os detentores de recursos competem vantajosamente com os que dele não dispõem" (idem, p. 194). Reconhecer a escola como território não tecnificado é reafirmar seu sentido formativo, situando o conhecimento como base para tanto. Ao professor caberia, pois, formar, em seu sentido pleno.

\section{O debate: algumas referências}

A questão atinente às TIC e a formação do professor nos remete ao debate sobre as bases desta profissão e a constituição da instituição escolar. Ao mesmo tempo, faz pensar na lógica que define os modos como são incorporadas as tecnologias neste lugar. Ademais das questões de acesso a determinados "bens tecnológicos" e das políticas públicas implementadas mais recentemente, com destaque para o uso das TIC, entender a produção tecnológica, a convergência de espaço/tempo em fluxos, que faz integrar o que estava fragmentado, enseja reflexões sobre o fenômeno, embora extenso, desigual, que atualiza e é atualizado na forma de rede.

Quais as conseqüências disso para a escola? O sentimento profundo de que a sociedade muda e de que as TIC anunciariam tempos outros, mais modernos para a escola. No entanto, as experiências com uso destas tecnologias são ainda localizadas e denotam a necessidade da "presença" do professor. O novo/ TIC atrita com a lógica escolar, na medida em que a rede em fluxo não é suficiente para sustentar a aprendizagem. Esta referência é crucial para o trabalho do professor, pois não basta que a informação circule, imprescindível tratá-la sistemática e continuamente. Carrear a informação de outra fonte que não a escolar significa apenas deslocamento em sua produção, absolutamente tratamento pedagógico. Nesse caso, a discussão retorna para o cerne do trabalho do docente. No território escola, ensinar e aprender são definitivos em sua configuração. Portanto, mais que questionar a natureza do trabalho do docente, a perspectiva de confluir rede e formação enseja debater o específico da escola, em congruência com a produção cultural em suas várias dimensões.

Ignorar a especificidade da escola como território formador e formativo, significar escola e as TIC, compreendendo o caráter técnico e 
instrumetalizador das tecnologias, tem como conseqüência sua utilização pedagógica, possibilitando reafirmar o território singular da escola e a autoridade do professor neste espaço.

Não se trata de negar a importância do desenvolvimento tecnológico, mas de questionar o papel central, muitas vezes atribuído às TIC, de serem potencialmente transformadoras das práticas dos docentes/escolares. É neste sentido que o trabalho do professor é esvaziado, submetido à aquisição de habilidades e competências profissionais. A idéia de que a informação e o conhecimento fluem rapidamente, dando lugar à inteligência coletiva, reconceitualiza o saber. As distinçóes entre dados, informação e saber se esfumaçam no vago e limitado conceito de informação, donde as indagaçōes: É isto que cabe à escola? É disto que se nutre o professor? Questóes como estas são essenciais para se pensar o repertório da formação de professores em tempos de rede e do discurso das TIC como panacéia educativa.

Recebido e aprovado em agosto de 2008.

\section{Notas}

1. Tecnologias da informação e comunicação. A sigla TIC tem sido utilizada com recorrência, daí seu uso no presente texto.

2. Disponível em: <http://portal.mec.gov.br/index2.php?option=com_content\&task=view \&id10820\&pop> Acesso em: 5 jul. 2008.

3. Isso se considerarmos, como faz Ianni (1996), as diferentes formas pelas quais os países são incorporados nesse processo.

4. Tomo de "empréstimo" o título de Hill (1987).

5. A idéia de rede, como sublinhado por Santos (1996), não é nova. Nova, neste caso, é a forma pela qual se configura.

6. Há toda uma mística em torno do uso de, por exemplo, blogs, mash-ups, podcast etc., vistos como recursos pedagógicos (cf. Richardson, 2006).

7. No trabalho de Josgrilberg (2006), as professoras falam da necessidade que têm de conversar com técnicos em informática, de aprender a trabalhar com os computadores, isto como situações que ensejam novas significações em sua prática pedagógica.

8. Diretrizes Curriculares Nacionais para a Formação de Professores da Educação Básica, em nível superior, curso de licenciatura, de graduação plena - Parecer CNP/CP 09/2001, p. 23.

9. Disponível em: <www.capes.gov.br/sobre/ctceb.html>. Acesso em: 23 jun. 2008.

Educ. Soc., Campinas, vol. 29, n. 104 - Especial, p. 747-768, out. 2008 
Tecnologias da informação e comunicação e formação de professores...

\section{Referências}

ABRAHAMSON, D.; BLIKSTEIN, P.; WILENSKY, U. Classroom model, model classroom: computer-supported methodology for investigating collaborative-learning pedagogy. In: CHINN, C.; ERKENS, G.; Puntambekar, S. (Ed.). Proceedings of the computer supported collaborative learning (CSCL) conference. Newark, NJ: Rutgers University, 2007. v. 8, part 1. p. 46-55.

AMSTRONG, A.; CASEMENT, C. A criança e a máquina: como os computadores colocam a educação de nossos filhos em risco. Trad. de Ronaldo Cataldo Costa. Porto Alegre: ARTMED, 2001.

BARRETO, R.G. Tecnologia e educação: trabalho e formação docente. Educação \& Sociedade, Campinas, v. 25, n. 89, p. 1181-1201, set./dez. 2004.

BAUERLEIN, M. The dumbest generation: how the digital age stupefies young Americans and jeopardizes our future - or don't trust anyone under 30. New York: Tarcher, 2007.

BELLONI, M.L. Educação a distância. Campinas: Autores Associados, 1999.

BLIKSTEIN, P.; ZUFFO, M.K. As sereias do ensino eletrônico. In: SILVA, M. (Org.). Educação online. São Paulo: Loyola, 2003. p. 23-38.

CARNEIRO, M.L.F.; MARASCHIN, C. Em busca de outro modelo para comunicação em rede. In: BARBOSA, R. (Org.). Ambientes virtuais de aprendizagem. Porto Alegre: ARTMED, 2005. p. 113-140.

CASTELLS, M. La Sociedad Red. Madrid: Alianza, 1998. (La era de la información: economia, sociedad y cultura, v. 1).

CASTELLS, M. A galáxia da internet: reflexōes sobre a internet, os negócios e a sociedade. Trad. de Maria Luiza Borges. Rio de Janeiro: Zahar, 2003.

CONTRERAS, J. La autonomía del profesorado. 2. ed. Madrid: Morata, 1999. 
COREA, C.; LEWKOWICZ, I. Pedagogía del aburrido: escuelas destituídas, familias perplejas. Buenos Aires: Paidós, 2004.

ESTEVE, J.M. O mal estar docente: a sala de aula e a saúde dos professores. São Paulo: EDUSC, 1999.

FREITAS, H.C.L. Certificação docente e formação do educador: regulação e desprofissionalização. Educação \& Sociedade, Campinas, v. 24, n. 85, p. 1095-1124, dez. 2003.

FUMAGALLI, L. Alianzas estratégicas para el desarrollo educativo local: el caso de la red de escuelas de Campana. In: Gatti, B. (Org.). Construindo caminhos para o sucesso escolar. Brasília, DF: UNESCO; INEP; MEC; CONSED, UNDIME, 2008. p. 147-159.

GILLERAN, A. Práticas inovadoras em escolas européias. In: SANCHO, J.M. et al. Tecnologias para transformar a educação. Trad. de Valério Campos. Porto Alegre: ARTMED, 2006. p. 85-109.

HILL, C. O mundo de ponta cabeça: idéias radicais durante a revolução inglesa de 1640. Trad. de Renato Janine Ribeiro. São Paulo: Cia das Letras, 1987.

IANNI, O. A era do globalismo. 2. ed. Rio de Janeiro: Civilização Brasileira, 1996.

JOSGRILBERG, F.B. O mundo da vida e as tecnologias de informação e comunicação na educação. 2006. 287f. Tese (Doutorado) - Escola de Comunicação e Artes, Universidade de São Paulo, São Paulo.

KENSKI, V. Educação e tecnologias: o novo ritmo da informação. Campinas: Papirus, 2007.

LÈVY, P. As tecnologias da inteligência: o futuro do pensamento na era da informática. Rio de Janeiro: Editora 34, 1993.

LIBÂNEO, J.C. Diretrizes curriculares da pedagogia: imprecisões teóricas e concepção estreita da formação profissional de educadores. $E d u$ cação \& Sociedade, Campinas, v. 27, n. 96, p. 843-876, out. 2006.

LUBAR, S. Infoculture: the Smithsonian book of information age inventions. Boston: Houghton, 1993. 
Tecnologias da informação e comunicação e formação de professores...

MATTELART, A. História da sociedade da informação. São Paulo: Loyola, 2001.

MCLUHAM, M. Os meios de comunicação como extensões do homem. Trad. de Décio Pignatari. 10. ed. São Paulo: Cultrix, 1995.

PALOFF, R.; PRATT, K. Construindo comunidades de aprendizagem no ciberespaço: estratégias eficientes para a sala de aula on-line. Porto Alegre: ARTMED, 2002.

PALOFF, R.; PRATT, K. O aluno virtual: um guia para trabalhar com estudantes on-line. Porto Alegre: ARTMed, 2004.

PONTE, J.P. Tecnologias de informação e comunicação na formação de professores: que desafios? Revista Iberoamericana de Educación, Madrid, n. 24, p. 63-90, sep./dec. 2000.

PRETTO, N. Formação de professores exige rede! Revista Brasileira de Educação, Rio de Janeiro, n. 20, p. 121-13, maio/ago. 2002.

RICHARDSON, W. Blogs, wikis, podcasts and other powerful web tools for classroom. Thousand Oaks: Corwin, 2006.

RODRIGUEZ, E.M. Los desafios docentes ante las nuevas tecnologías. In: Arranz, L. El libro texto: materiales didácticos. Madrid: Universidad Complutense, 1996. t. 1, p. 108-118.

SANCHO, J.M. Tecnologias da informação e comunicação a recursos educativos. In: SANCHO, J.M. et al. Tecnologias para transformar a educação. Trad. de Valério Campos. Porto Alegre: ARTMED, 2006. p. 15-41.

SANTOS, M. A natureza do espaço. 2. ed. São Paulo: HUCitec, 1996.

SCHEIBE, L. Formação de professores: dilemas da formação inicial a distância. Educere et Educare, Cascavel, v. 1, p. 199-212, 2006.

SILVA, T.E.; FREIRE, F.; ALMEIDA, R.Q. (Coord.). A leitura nos oceanos da internet. São Paulo: Cortez, 2003.

ZUIN, A.A.S. Educação a distância ou educação distante?: o Programa Universidade Aberta do Brasil, o tutor e o professor virtual. Educação \& Sociedade, Campinas, v. 27, n. 96, p. 935-954, out. 2006. 